\title{
Physician Scientist Award (Program) (PSA)
}

National Cancer Institute

\section{Source}

National Cancer Institute. Physician Scientist Award (Program) (PSA). NCI Thesaurus. Code C20007.

Designed to take individuals with clinical degrees and give them experience in clinical research. 